\title{
Polyacrylate as Functional Binder for Silicon and Graphite Composite Electrode in Lithium-Ion Batteries
}

\author{
Shinichi Komaba, ${ }^{*}$ Tomoaki OzekI, Naoaki YabuUchI, and Keiji Shimomura
}

Department of Applied Chemistry, Tokyo University of Science (Shinjuku Tokyo 162-8601, Japan)

Received September 27, 2010 ; Accepted October 26, 2010

\begin{abstract}
Polyacrylates were applied as binder for the electrode of a particulate mixture of silicon, graphite, and Ketjen black for lithium-ion batteries. We found that poly(alkali acrylate) binder remarkably improved the electrochemical lithiation and delithiation performance of the silicon-graphite electrode compared to that of conventional binders. The polyacrylate coating on $\mathrm{Si}$ and graphite particles suppressed the electrode deterioration. When the electrode was prepared with $30 \mathrm{wt} \%$ poly(sodium acrylate) binder, the higher specific capacity and initial efficiency were obtained with much improved cycleability.
\end{abstract}

Key Words : Silicon, Polyacrylate, Binder, Lithium-ion Battery

\section{Introduction}

Since silicon undergoes electrochemical lithiation to form Si-Li alloys, silicon based materials are one of the potential candidates as negative electrode for lithium-ion batteries. When Si-Li alloys are electrochemically formed at $\mathrm{Si}$ electrode, the capacity is expected to be higher than that of the carbonaceous materials. ${ }^{1)}$ However, the silicon electrode suffers from a large volume change during successive cycle, leading to cracking and pulverization of silicon, ${ }^{2)}$ which result in capacity fading. To solve this problem, nano-silicon, ${ }^{3)}$ carbon-coated sili$\mathrm{con}^{4)}$ and so on were previously reported. Furthermore, silicon thin films exhibited an excellent charge-discharge cycling behavior. ${ }^{5,6}$ In recent years, the selection of polymeric binders is known to be important to improve the battery performance of particulate silicon. As previously reported, ${ }^{7-9)}$ sodium carboxymethyl cellulose (CMC$\mathrm{Na}$ ) is already known to be potential binder for silicon electrode.

We have investigated the surface passivation layer, ${ }^{10)}$ so-called SEI, and we proposed functional binders ${ }^{11-13)}$ acting as the artificial SEI at graphite electrodes, such as poly(acrylic acid). ${ }^{12)}$ We pointed out that the polymer chain conformation of polyacrylate is important to modify the graphite surface ${ }^{13)}$ and that poly(lithium acrylate) (PAALi) and poly(sodium acrylate) (PAANa) binders enhance the rate performance of nitroxide radical polymer electrode in Li cells. ${ }^{14)}$ It is interesting that electrochemical performance of the Si and Sn based electrodes is also improved by polyacrylate binder as described by our group ${ }^{15)}$ and Dahn's group, ${ }^{16)}$ respectively. In this paper, we applied the poly(alkali acrylate)s as binder for the particulate silicon based negative electrode to improve the battery performance of lithium-ion batteries.

\section{Experimental}

Silicon (particle size is $<100 \mathrm{~nm}$ Aldrich Co.), natural graphite (particle size is $3 \mu \mathrm{m}$, SEC Carbon Corp.), and

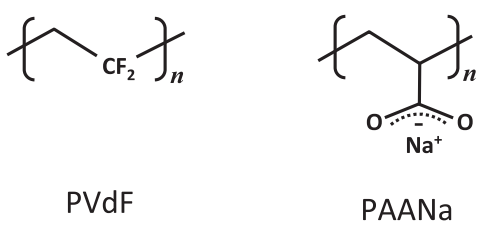

Fig. 1 Molecular structures of the polymeric binders.

Ketjen black (KB) (Lion Corp.) were used as received. Poly(vinylidene fluoride) (PVdF) (Polysciences, Inc.), CMCNa (Daicel Chemical Industries, Ltd.), and PAANa (Kishida Chemical Co., Ltd., polymerization degree: 22000-66000) were used as binders. The molecular structure of PAANa is shown and compared with PVdF in Fig. 1. Polyacrylates of lithium, sodium, and potassium salts were prepared as previously described ${ }^{13)}$ for comparison.

For electrode preparation, silicon, graphite, and KB were thoroughly mixed, and the binders were added to the particulate mixture to make the slurry by adding water and N-methylpyrrolidinon for polyacrylates and $\mathrm{PVdF}$, respectively. The slurry was cast on $\mathrm{Cu}$ foil and dried at $150{ }^{\circ} \mathrm{C}$ in vacuum, followed by roll pressing. The loading on $\mathrm{Cu}$ foil was $c a .1 \mathrm{mg} \mathrm{cm}^{-2}$. The weight ratio of electrode mixture was adjusted as Si:graphite: KB:binder $=20:(70-x): 10: x$ (wt \%). The specific capacities are calculated on the basis of the weight of silicon and graphite. The coin-type cell was fabricated in Ar-filled glovebox and consisted of the prepared electrode, lithium foil electrode, and $1 \mathrm{~mol} \mathrm{dm}^{-3} \mathrm{LiPF}_{6}$ ethylene carbonate/dimethyl carbonate (1:1 by volume) solution with separator. Electrochemical measurement of Li cells was carried out at room temperature around $25^{\circ} \mathrm{C}$. Current reversal chronopotentiometry was successively carried out at a rate of $-50 \mathrm{~mA}$ and $50 \mathrm{~mA}$ ( $\mathrm{g}$ of silicon and graphite $^{-1}$ in the potential region between 2.00 and 0.00 $\mathrm{V}$ except the initial electroreductive lithiation. The initial lithiation was done by the $\mathrm{CC}-\mathrm{CV}$ mode, that is, a 
constant current (CC) of $-50 \mathrm{~mA} \mathrm{~g}^{-1}$ was applied until approaching $25 \mathrm{mV}$, and then the constant voltage (CV) of $25 \mathrm{mV}$ was kept prior to delithiation. The total duration of CC-CV was fixed for $30 \mathrm{~h}$ to control the total capacity less than $1500 \mathrm{mAh} \mathrm{g}^{-1}$. Laser Raman microscope (RAMANplus, Nanophoton Co., Japan, 532 nm laser radiation) was employed to observe electrode morphology and Raman spectra.

\section{Results and Discussion}

Generally, conventional PVdF binder is known to be crystalline polymer ${ }^{17)}$ and the polymeric molecular chains are bound into bundle (crystallized) during drying the slurry, so that the active material is not completely covered by PVdF. On the contrary, the whole active material is covered with amorphous poly(alkali acrylate) thin layer like glue as we previously described. ${ }^{12,13)}$ The polyacrylate layer on graphite electrode behaves as artificial solid-electrolyte interphase (SEI), as a result, lithium intercalation into the graphite in the propylene carbonate and organic ionic liquid media containing no film forming additives was attained by the polyacrylate. ${ }^{11}$

We applied PAANa as the binder for the mixture of silicon, graphite, and KB. In Fig. 2, the initial irreversible capacity between 1.0 and $0.5 \mathrm{~V}$ was clearly reduced by PAANa, which modifies the surface of the Si-based electrode including the SEI. The initial coulombic efficiencies were improved by adopting polyacrylate binder, i.e., $50,65,65$, and $75 \%$ for $10 \% \mathrm{PVdF}, \mathrm{CMCNa}$, and PAANa and $30 \%$ PAANa electrodes, respectively, showing that the polyacrylate suppresses the electrolyte decomposition at the initial cycle not only for graphite ${ }^{12)}$ but also for Si-graphite electrode.

Figure 3 (upper) shows chronopotentiograms at the tenth cycle of the PVdF, CMCNa and PAANa electrodes. In all cases, the redox couple appears in the same voltage region between 0.8 and $0 \mathrm{~V}$, which is typically observed for the mixed electrode of silicon and graphite,

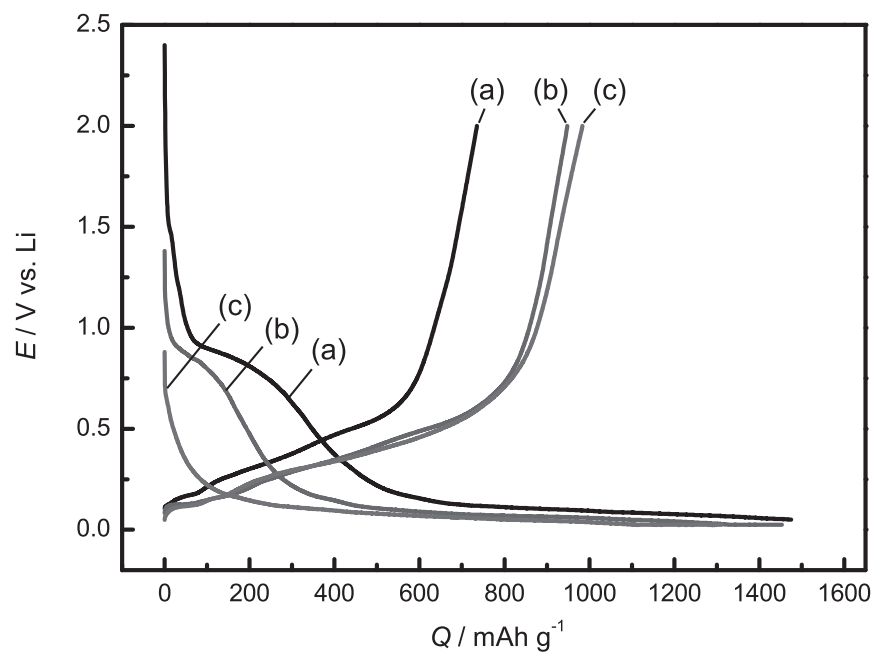

Fig. 2 Initial current reversal chronopotentiograms of silicon-graphite electrodes prepared with (a) PVdF (10 wt \%), (b) $\mathrm{CMCNa}(10 \mathrm{wt} \%$ ), and (c) PAANa (30 wt \%). and the redox activity is due to the combination of lithium intercalation into graphite and Si-Li alloy formation. However, the specific capacity depends on the binders. The capacity was less than 400 and $800 \mathrm{mAh} \mathrm{g}^{-1}$ for $\mathrm{PVdF}$ and $\mathrm{CMCNa}$, respectively. In contrast, the PAA$\mathrm{Na}$ electrode exhibited the highest activity of approximately $1000 \mathrm{mAh} \mathrm{g}^{-1}$. The similar electrochemical results were confirmed for the Si-graphite electrodes with poly(sodium acrylate), poly(lithium acrylate), and poly(potassium acrylate) binders. Since the theoretical limit of the lithium intercalation forming $\mathrm{LiC}_{6}$ is as low as $372 \mathrm{mAh} \mathrm{g}^{-1}$, the higher capacity for the PAANa resulted from the stable and reversible redox due to the lithiation of Si. From the potential variation during lithiation below $0.3 \mathrm{~V}$ in Fig. 3, the potential plateaux corresponding to staging Li intercalated graphite compounds ${ }^{18}$ more clearly appear for the PVdF than the PAANa, suggesting that the electrochemical activity of Li-Si alloy is readily depressed during the initial ten cycles for PVdF.

Figure 3 (lower) shows the change in the reversible capacity of silicon-graphite mixture bound by three polymeric compounds. By comparing the $10 \mathrm{wt} \%$ binder electrodes for PVdF, CMCNa, and PAANa, the PAANa binder is the most suitable to retain the lithiation capacity. In case of PVdF, the capacity was drastically decreased during 10 cycles from 900 to $300 \mathrm{mAh} \mathrm{g}^{-1}$. As
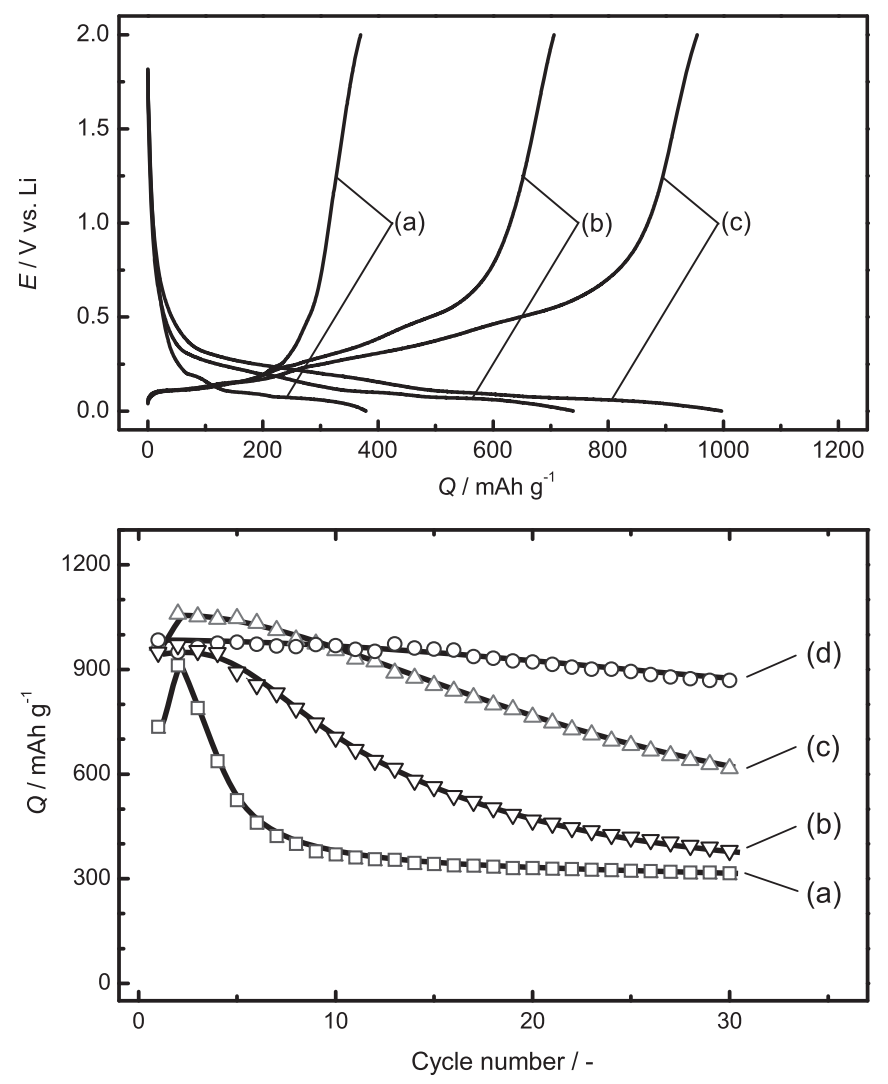

Fig. 3 (upper) Current reversal chronopotentiograms at the tenth cycle and (lower) variation in reversible oxidation capacities of silicon-graphite electrodes prepared with (a) $10 \mathrm{wt} \% \mathrm{PVdF}$ and (b) $10 \mathrm{wt} \% \mathrm{CMCNa}$, and (c) 10 and (d) $30 \mathrm{wt} \%$ PAANa binder. 
mentioned above, the activity at the 10th cycle is mainly due to lithium intercalation into graphite, indicating that the decrease in capacity is responsible for the silicon component. Such behavior of particulate $\mathrm{Si}$ is considered to be due to collapse of Si particle and fatigue of the composite electrode resulting from the large volume change by lithiation cycle. When $\mathrm{CMCNa}$ binder was used, the initial capacity was similar to that of PVdF and the better capacity retention was obtained, which should be due to the improved binding ability according to previous reports.9. The gradual decrease of capacity was observed for the CMCNa electrode, and its capacity was not remarkably different from that of PVdF after 30 cycles.

By adopting the polyacrylate binder, the cycle performance is improved as seen in Fig. 3. For $10 \mathrm{wt} \%$ PAA$\mathrm{Na}$, the capacity was approximately $1000 \mathrm{mAh} \mathrm{g}^{-1}$ at the first cycle and reduced to $600 \mathrm{mAh} \mathrm{g}^{-1}$ after thirty cycles. If graphite $(60 \%)$ is assumed to show $372 \mathrm{mAh}(\mathrm{g}$ of graphite $)^{-1}$, the specific capacity of silicon (20\%) in the PAANa electrode is calculated to be approximately $2880 \mathrm{mAh} \mathrm{g}$ of silicon $)^{-1}$ at the first cycle. When the (a)

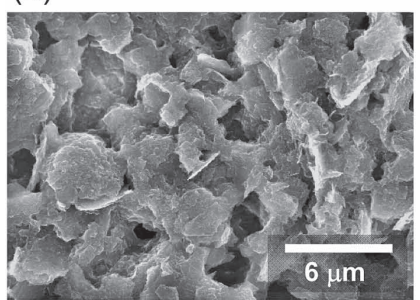

(b)

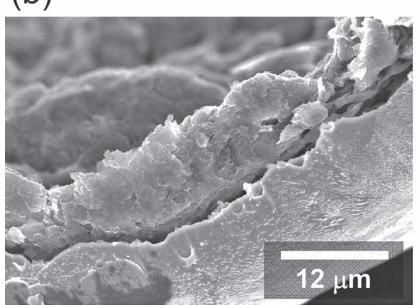

(c)

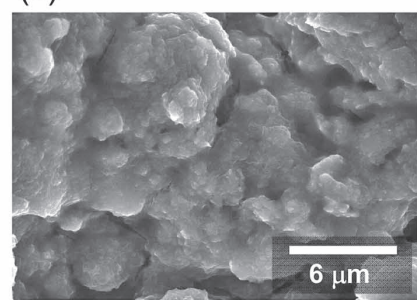

(d)
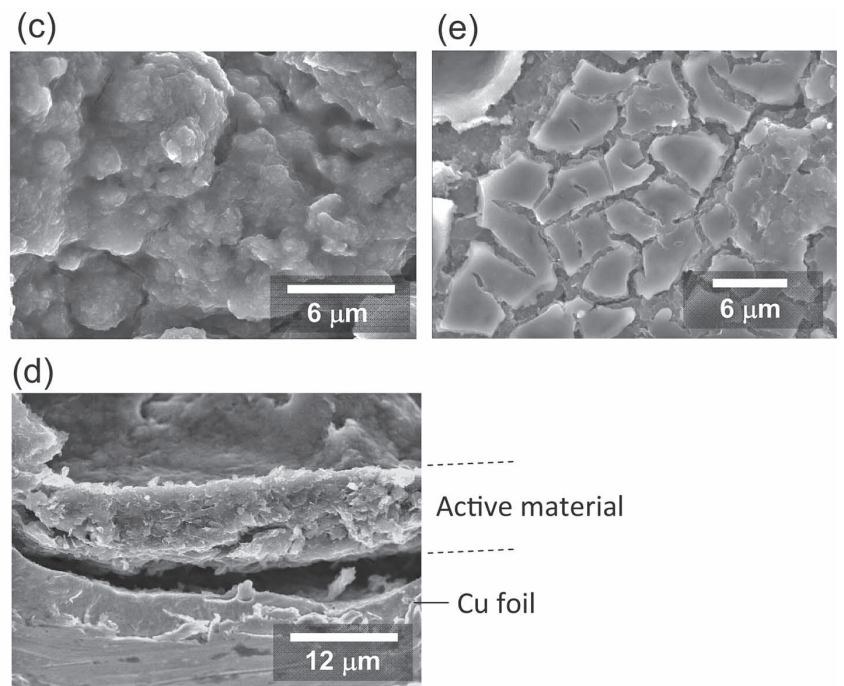

Fig. 4 SEM images of the Si-graphite electrodes with 30 wt \% PAANa binder (a)(b) before cycle and (c)(d) after 10 cycles; (a)(c) surface and (b)(d) cross sectional images. An image of $10 \mathrm{wt} \% \mathrm{PVdF}$ electrode after 10 cycles is shown in (e) for comparison.

(a)

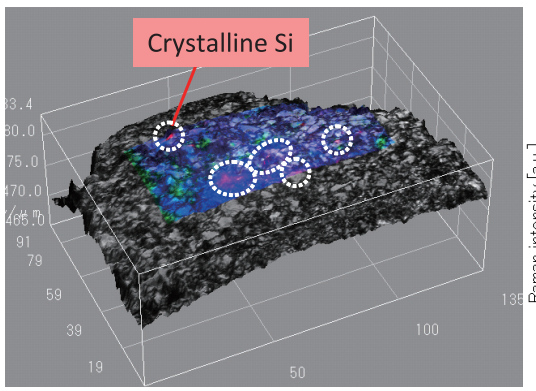

(b)

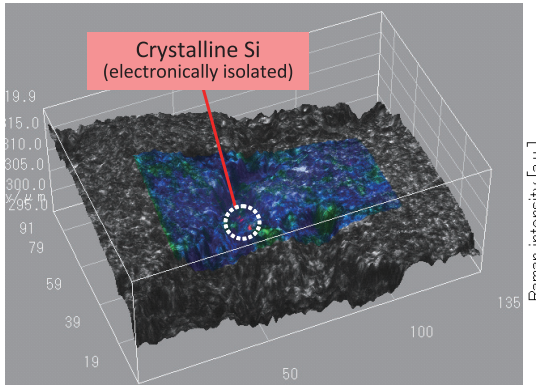

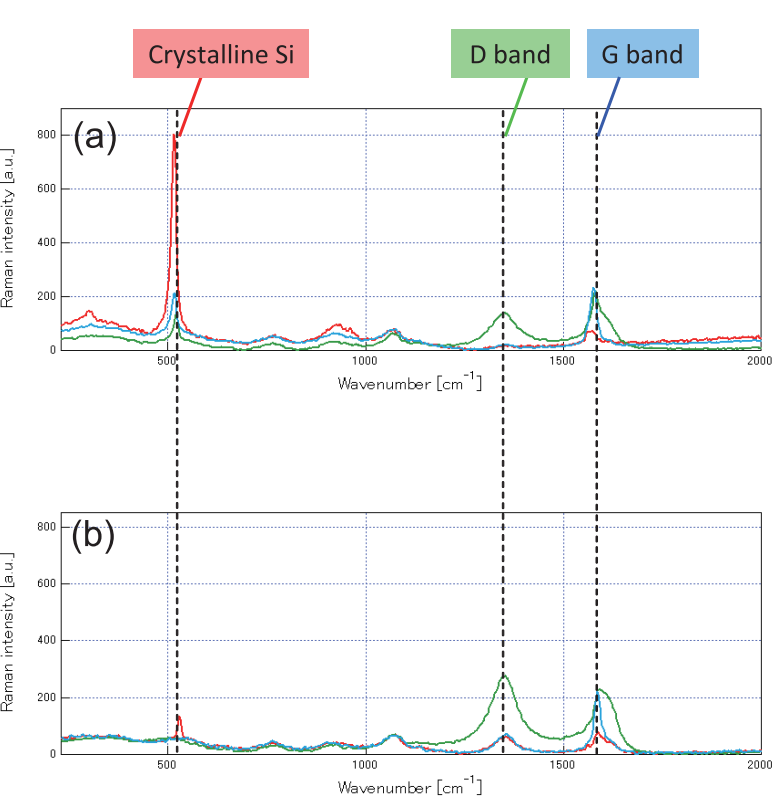

Fig. 5 (left) Superimposed images of optical and Raman microscopy, in which red, blue, and green portions correspond to appearance of Raman peaks of crystalline silicon, G-band of carbon, and D-band of carbon respectively, and (right) laser Raman spectra of selected points of Si-graphite electrodes with $10 \mathrm{wt} \% \mathrm{PVdF}$ binder (a) before initial cycle and (b) after 10 cycles. 
amount of PAANa increases to $30 \mathrm{wt} \%$, the silicon based electrode demonstrated the reversible capacity of ca. $870 \mathrm{mAh} \mathrm{g}^{-1}$ at the 30th cycle which corresponds to almost $90 \%$ of the initial capacity. We confirmed that the increase of PVdF binder up to $30 \mathrm{wt} \%$ did not improve the electrode performance at all, suggesting the different functionality of PVdF and PAANa binder. The reversible capacity was much increased by increase in the silicon content in the PAANa electrode. Indeed, the PAANa strongly binds the particulate electrode materials and improves the adhesion strength onto $\mathrm{Cu}$ foil compared to the $\mathrm{PVdF}$ and $\mathrm{CMCNa}$, and the adhesion strength increased with the increase in the amount of PAANa from 10 to $30 \mathrm{wt} \%$, as confirmed by peel test.

We observed the morphological change of the electrodes by SEM. Figure 4 shows that the graphite particles, whose size is about approximately $3 \mu \mathrm{m}$, are distinguishable at the surface of the pristine electrode and the thickness was about $10 \mu \mathrm{m}$. The electrolyte decomposition during 10 cycles resulted in the deposition for the PAANa in Fig. 4 (c), but the larger amount of deposit covering the electrode surface is observed and the deposited layer is cracked for PVdF in Figure 4 (e). This should be one of origins of the severe deterioration for PVdF. From the cross sectional image, the electrode thickness of the PAANa hardly increased after tests, namely, there appears to be no apparent damage of the active material layer.

From Raman spectra, the crystalline Si remained after 10 cycles in case of PVdF, whereas crystalline Si disappeared for PAANa because of the amorphization of Si by lithiation and delithiation. In Fig. 5, laser Raman microscope observation proved that crystalline silicon partly distributed and remained after 10 cycles for PVdF, suggesting that a part of the crystalline silicon did not undergo lithiation due to electrical isolation. It is speculated that the lithiation of $\mathrm{Si}$ accompanied with severe electrolyte decomposition during the initial cycles leads to large volume expansion, resulting in partially electric isolation of silicon. It is in good agreement with the different electrochemical performances for PVdF and PAANa.

As described previously, ${ }^{12,13)}$ the uniform polyacrylate layer formed on graphite contributes the suppression of irreversible side reaction and desolvation of $\mathrm{Li}^{+}$ions solvated with carbonate ester, so that highly reversible lithium intercalation. In this study, the graphite and $\mathrm{Si}$ particles are coated by polyacrylate which was evidenced by surface analyses. When silicon particles expand by electrochemical lithiation, the uniform polyacrylate coating should suppress the electrical isolation of silicon within the electrode. We believe that the polyacrylate suppresses the electrolyte decomposition not only on graphite but also on lithiated silicon surface, ${ }^{15)}$ which contributes to the higher initial efficiency as described in Fig. 2. It is likely that the chemical and physical crosslink of polyacrylate is developed because of its amorphous and dehydration nature. The complex effec- tiveness of polyacrylate affected by molecular structure including crosslink, slurry structure, binding condition, adhesion state onto current collector, crystallinity, swelling with electrolyte etc. realized the improvement of particulate silicon based electrode. Further investigation is under progress to enhance the battery performance and understand the role of functional binders. The binder chemistry for lithium ion batteries has high potential to enhance the battery performance and to control interface structure including SEI.

\section{Acknowledgments}

The authors thank Mr. Tomoya Uchiyama (Nanophoton Co., Japan) for laser Raman microscope observation. This study was supported by KAKENHI (No. 21750194) and NEDO, Japan.

\section{References}

1) R. A. Sharma and R. N. Seefurth, J. Electrochem. Soc., 123, 1763 (1976).

2) M. Winter and J. O. Besenhard, Electrochim. Acta, 45, 31 (1999).

3) H. Li, X. J. Huang, L. Q. Chen, Z. Wu, and Y. Liang, Electochem. Solid-State Lett., 2, 547 (1999).

4) M. Yoshio, H. Wang, K. Fukuda, T. Umeno, N. Dimov, and Z. Ogumi, J. Electrochem. Soc., 149, 1598 (2002).

5) T. Takamura, S. Ohara, M. Uehara, J. Suzuki, and K. Sekine, J. Power Sources, 129, 96 (2004).

6) S. Komaba, F. Mikami, T. Itabashi, M. Baba, T. Ueno, and N. Kumagai, Bull. Chem. Soc. Jpn., 79, 154 (2006).

7) L. B. Chen, X. H. Xie, J. Y. Xie, K. Wang, and J. Yang, J. Appl. Electrochem., 36, 1099 (2006).

8) J. Li, R. B. Lewis, and J. R. Dahn, Electrochem. SolidState Lett., 10, A17 (2007).

9) N. S. Hochgatterer, M. R. Schweiger, S. Koller, P. R. Raimann, T. Wohrle, C. Wurm, and M. Winter, Electrochem. Solid-State Lett., 11, A76 (2008).

10) S. Komaba, T. Itabashi, T. Ohtsuka, H. Groult, N. Kumagai, B. Kaplan, and H. Yashiro, J. Electrochem. Soc., 152, A937 (2005).

11) S. Komaba, N. Yabuuchi, T. Ozeki, K. Okushi, H. Yui, K. Konno, Y. Katayama, and T. Miura, J. Power Sources, 195, 6069 (2010).

12) S. Komaba, T. Ozeki, and K. Okushi, J. Power Sources, 189, 197 (2009).

13) S. Komaba, K. Okushi, T. Ozeki, H. Yui, Y. Katayama, T. Miura, T. Saito, and H. Groult, Electrochem. SolidState Lett., 12, A107 (2009).

14) S. Komaba, T. Tanaka, T. Ozeki, T. Taki, H. Watanabe, and H. Tachikawa, J. Power Sources, 195, 6212 (2010).

15) T. Ozeki, K. Shimomura, S. Komaba, H. Yui, Y. Katayama, and T. Miura, The $76^{\text {th }}$ Annual Meeting of the Electrochemical Society of Japan, Abstr., 1P07, p.357 (2009) [in Japanese].

16) J. Li, D.-B. Le, P. P. Ferguson, and J. R. Dahn, Electrochem. Acta, 55, 2991 (2010).

17) W. Ma, J. Zhang, and X. Wang, J. Mater. Sci., 43, 398 (2008).

18) S. Komaba, T. Itabashi, M. Watanabe, H. Groult, and N. Kumagai, J. Electrochem. Soc., 154, A322 (2007). 